\title{
Synthesis and acaricidal activity of cyenopyrafen and its geometric isomer
}

\author{
Haibo Yu, Man Xu, Yan Cheng, Hongfei Wu, Yanmei Luo, and Bin Li* \\ State Key Laboratory of the Discovery and Development of Novel Pesticide, \\ Shen Yang Research Institute of Chemical Industry Co. Ltd., Shenyang 110021, \\ People's Republic of China \\ E-mail: libin1@sinochem.com
}

\begin{abstract}
Cyenopyrafen and its geometric isomer were synthesized by various methods, and the structures were characterized by ${ }^{1} \mathrm{H}$ NMR. ${ }^{13} \mathrm{C}$ NMR, IR, elemental analyses and X-ray diffraction analyses. The bioassay tests showed that cyenopyrafen exhibited a higher acaricidal activity than its isomer. Cyenopyrafen can be isomerized from the $Z$ form in the presence of a base.
\end{abstract}

Keywords: Cyenopyrafen, geometric isomer, synthesis, acaricidal activity

\section{Introduction}

Nissan Chemicals Co. has been investigating the insecticidal, acaricidal, nematicidal and aquatic antifouling properties of acrylonitrile derivatives since 1995. In January 2006, cyenopyrafen was provisionally approved for the ISO name of a new acaricide. Cyenopyrafen is the first commercialized acrylonitrile derivative with important acaricidal activity against spider mites (Tetranychus cinnabarinus). It has also a high safety level on beneficial insects such as honey bees. $^{1,2}$ In 2009, cyenopyrafen was launched under the trade name Starmite, besides in Japan, it is also used in Korea. 


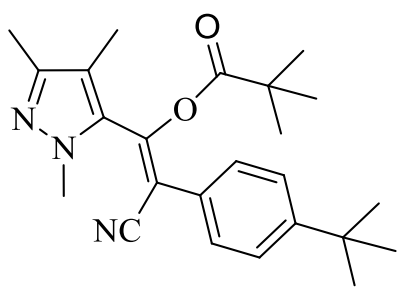

Figure 1. Cyenopyrafen (CODE NOS: NC-512).

The double bond in the acrylonitrile compounds can occur as two geometric isomers referred to as the $E$ - and $Z$-isomer. Cyenopyrafen exits in the $E$ configuration. The properties of both of them, with regard to physiological activity, safety and physical properties often differ from each other. ${ }^{3,4}$ In order to study the differences of their biological activity of cyenopyrafen and its geometric isomer, the synthesis of the two isomers was conducted by two methods, and the acaricidal activity relationship of cyenopyrafen and its $Z$ isomer was discussed. In order to reuse the $Z$ isomer, we also studied the method of isomerization from $Z$ - to the E-isomer.

\section{Result and Discussion}

\section{Chemistry}

2-(4-tert-Butylphenyl)-3-hydroxy-3-(1,3,4-trimethyl-1 $H$-pyrazol-5-yl)acrylonitrile $\quad \mathbf{3}$ was prepared according to Scheme 1 1,3,4-trimethyl-1H-pyrazole-5-carboxylate $\mathbf{1}^{5-12}$ and 2-(4-tert-butylphenyl)acetonitrile 2 were subjected to the condensation reaction using sodium methoxide as base to give 3-hydroxyacrylonitrile $\mathbf{3}$ in good (90\%) yield. ${ }^{13,14}$

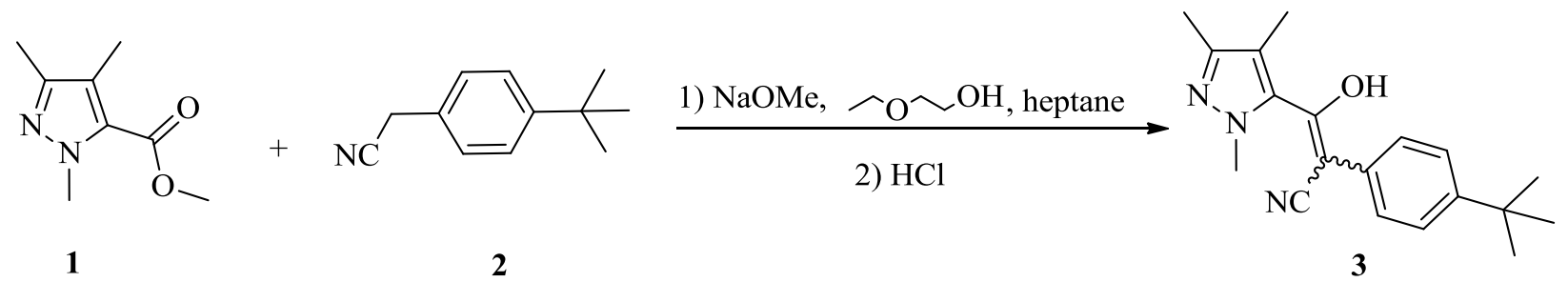

Scheme 1. Synthesis of 2-(4-tert-butylphenyl)-3-hydroxy-3-(1,3,4-trimethyl-1H-pyrazol-5yl)acrylonitrile 3.

To synthesize cyenopyrafen or its geometric isomer as the major product, two methods were explored (Scheme 2 and 3). Cyenopyrafen 4 was synthesized as described in the literature and can readily be achieved by the reaction of 3-hydroxyacrylonitrile $\mathbf{3}$ with 2,2-dimethyl propionyl 
chloride in the presence of a base such as $\mathrm{Et}_{3} \mathrm{~N}$ at room temperature (Scheme 2) in good (93\%) yield. ${ }^{14}$ A new method consisted in the synthesis of cyenopyrafen's geometric isomer $\mathbf{5}$ by reacting 3-hydroxyacrylonitrile 3 with 2,2-dimethylpropionic acid via a Steglich esterification in the presence of DMAP at room temperature in $65 \%$ yield, using DCC as a dehydration reagent (Scheme 3). The carboxylic acid reacts with DCC to a O-acyl isourea, which is more reactive than the free acid. The alcohol attacks this intermediate, forming DCU and the corresponding ester. To suppress this reaction, DMAP is added, acting as an acyl transfer-reagent. The reaction mechanism is described in Scheme 4.
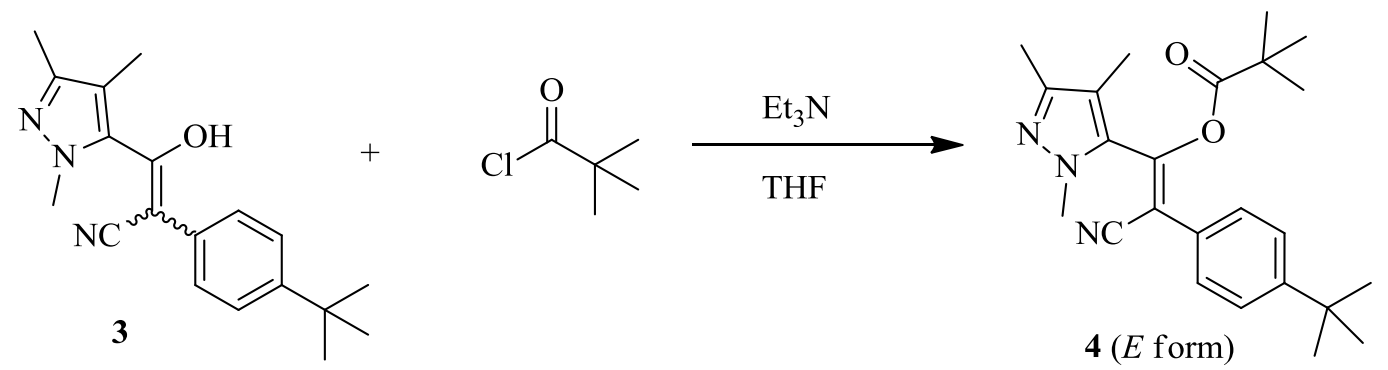

Scheme 2. Synthesis of (2E)-3-(2,2-dimethypropanoyloxy)-2-(4-tert-butylphenyl)-3-(1,3,4trimethylpyrazol-5-yl)acrylonitrile 4 (cyenopyrafen).
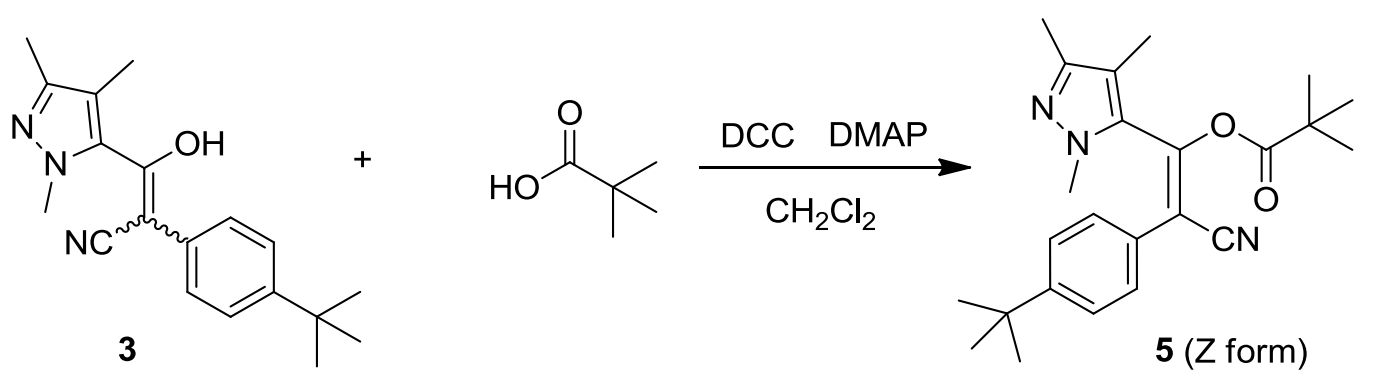

Scheme 3. Synthesis of (2Z)-3-(2,2-dimethypropanoyloxy)-2-(4-tert-butylphenyl)-3-(1,3,4trimethylpyrazol-5-yl)acrylonitrile $\mathbf{5}$ ( $Z$ form).

In order to valorize the $Z$ form, we also studied the isomerization from the $Z$ form to the $E$ form. Cyenopyrafen $\mathbf{4}$ can be obtained by isomerization from the $Z$ form $\mathbf{5}$ in a polar solvent, such as acetonitrile and methanol under heating conditions, in $48 \%$ yield in the presence of an organic base, such as pyridine or DMAP (Scheme 5). The isomerization was catalyzed by paramagnetic molecules DMAP and the possible mechanism was shown in scheme $\mathbf{6}^{19}$ 

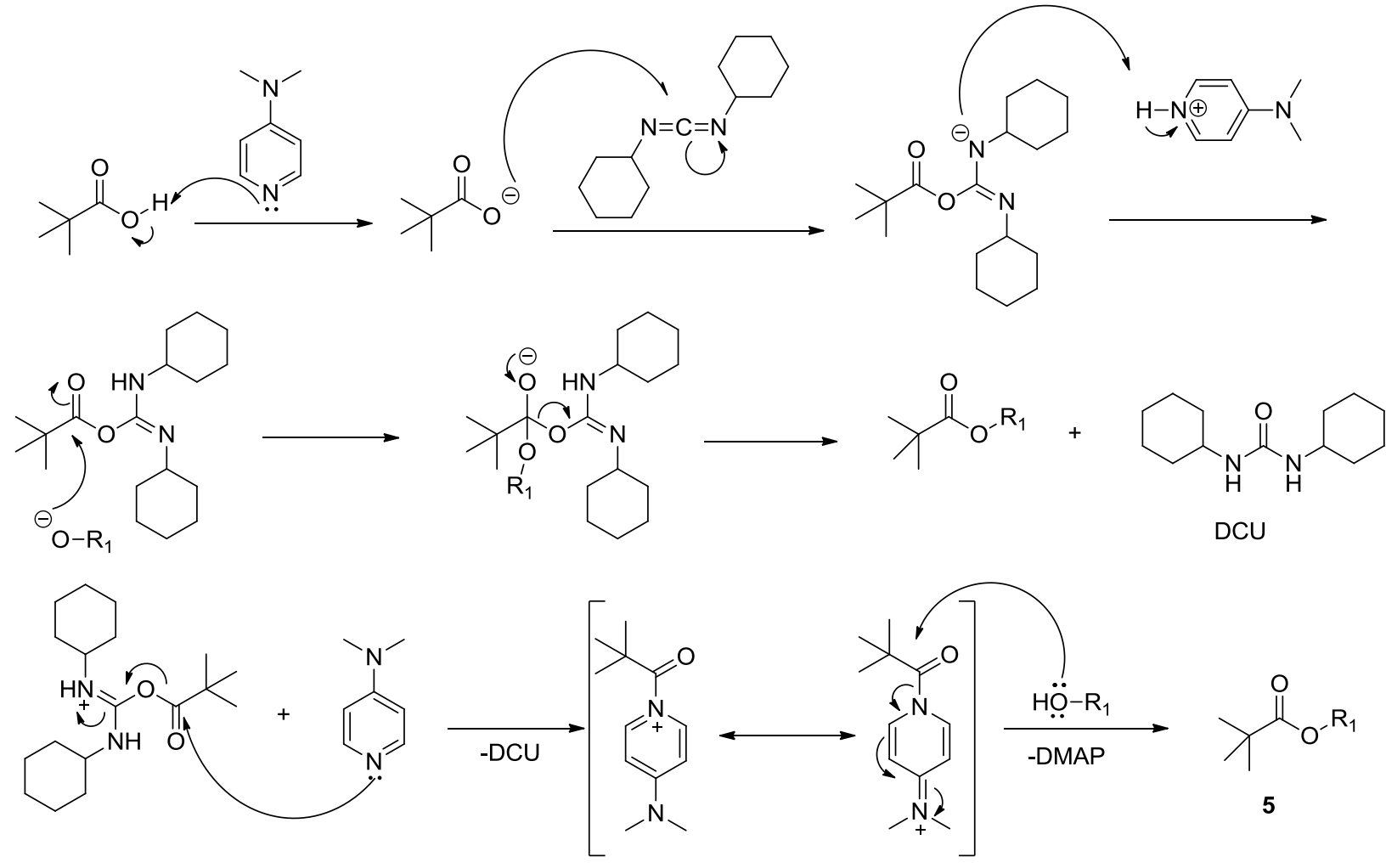

Scheme 4. Mechanism of synthesis 5.<smiles>Cc1nn(C)c(/C(OC(=O)C(C)(C)C)=C(/C#N)c2ccc(C(C)(C)C)cc2)c1C</smiles>

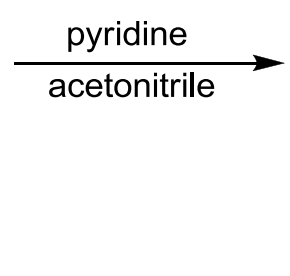<smiles>Cc1nn(C)c(/C(OC(=O)C(C)(C)C)=C(\C#N)c2ccc(C(C)(C)C)cc2)c1C</smiles>

Scheme 5. Isomerization from the $Z$ form 5 to cyenopyrafen 4.

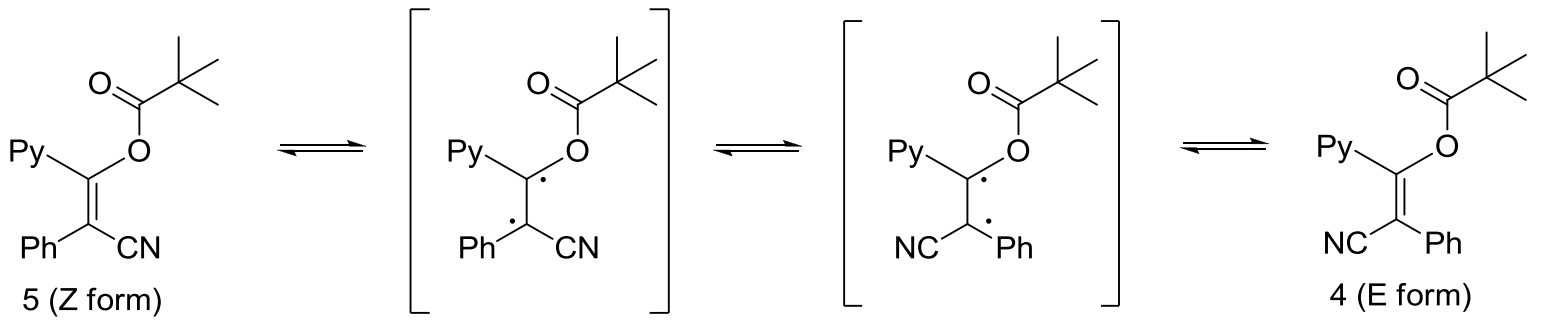

Scheme 6. Possible mechanism of isomerization. 
The synthesized compounds were identified by ${ }^{1} \mathrm{H}$ NMR, ${ }^{13} \mathrm{C}$ NMR, IR, and elemental analysis. The characteristic signals resulting from the $\mathrm{C} \equiv \mathrm{N}$ group of cyenopyrafen and its isomer are at 115.29 and $116.21 \mathrm{ppm}$ respectively in the. ${ }^{13} \mathrm{C}$ NMR spectrum and IR spectra displayed a strong $\mathrm{C} \equiv \mathrm{N}$ group absorption at 2210 and $2220 \mathrm{~cm}^{-1}$. In order to further confirm the structure of the cyenopyrafen and its isomer, the X-ray diffraction analyses were carried out. The crystal structures of cyenopyrafen and its isomer are shown in Figure 2 and 3.

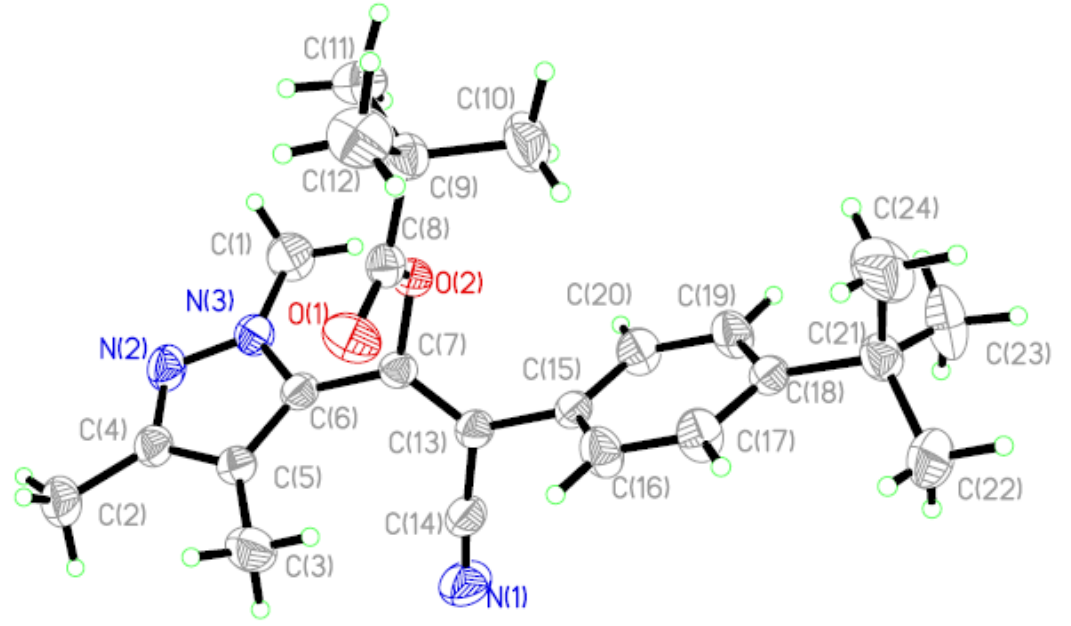

Figure 2. The crystal structure of cyenopyrafen 4 ( $E$ form).

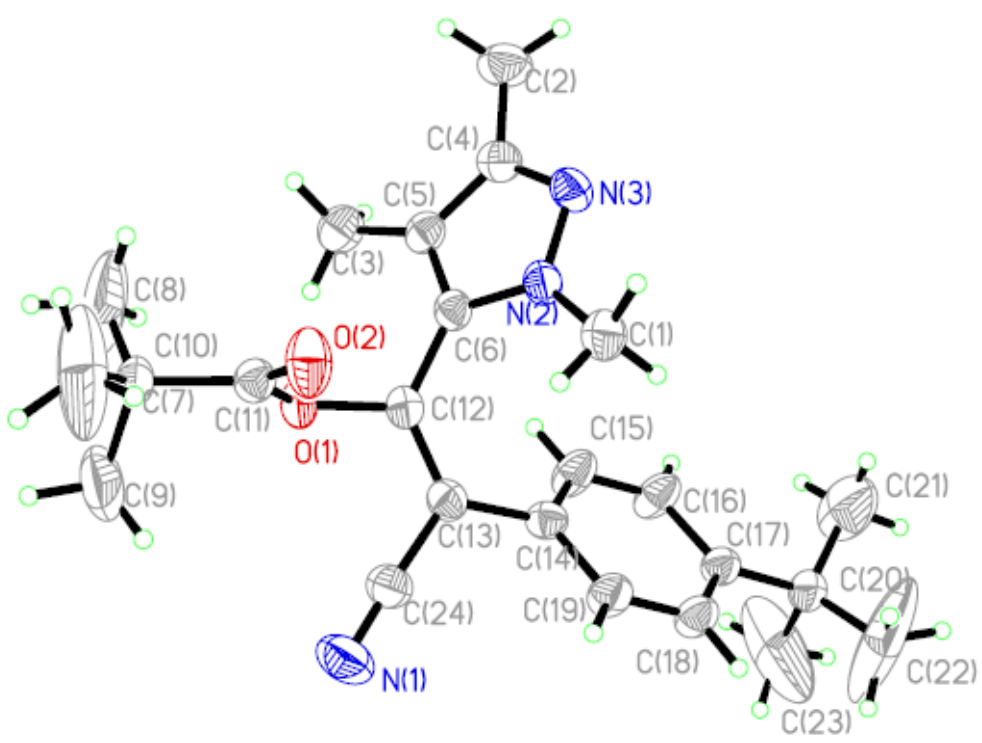

Figure 3. The crystal structure of cyenopyrafen's isomer 5 ( $Z$ form). 


\section{Bioactivity}

Cyenopyrafen and its isomer were tested for their acaricidal activities against spider mites (Tetranychus cinnabarinus). The results of acaricidal activities are listed in Table 1. The bioassay tests showed that both cyenopyrafen and its isomer exhibit an excellent acricidal activity, but cyenopyrafen has a better acricidal activity compared to its $Z$ form. These data show that their acaricidal activity is strongly influenced by the configuration of the double bond.

Table 1. Acaricidal activity against spider mites of cyenopyrafen and its isomer ${ }^{\mathrm{a}}$

\begin{tabular}{cccccc}
\hline \multirow{2}{*}{ Compound } & \multirow{2}{*}{ Configuration } & \multicolumn{5}{c}{ Mortality $(\%)$} \\
\cline { 3 - 6 } & & $5 \mathrm{mg} / \mathrm{L}$ & $2.5 \mathrm{mg} / \mathrm{L}$ & $1.25 \mathrm{mg} / \mathrm{L}$ & $0.625 \mathrm{mg} / \mathrm{L}$ \\
\hline Cyenopyrafen & $E$ & 100 & 100 & 85 & 0 \\
$\begin{array}{c}\text { Cyenopyrafen's } \\
\text { isomer }\end{array}$ & $Z$ & 100 & 100 & 55 & 0
\end{tabular}

${ }^{\mathrm{a}} 0$ equals to no activity; 100 equals to total control.

\section{Conclusions}

Cyenopyrafen and its isomer were synthesized. The structures were identified by ${ }^{1} \mathrm{H}$ NMR, ${ }^{13} \mathrm{C}$ NMR, IR, elemental analysis, and X-ray diffraction analyses. The bioassay results show that the acricidal activity of cyenopyrafen is better than its isomer.

\section{Experimental Section}

General. Melting points were measured by using a RY-1 melting point apparatus and are uncorrected. ${ }^{1} \mathrm{H}$ NMR and ${ }^{13} \mathrm{C}$ NMR spectra were recorded on a Varian-300 spectrometer using TMS as an internal reference. Chemical shift values $(\delta)$ were given in ppm. Elemental analyses were performed on a Yananca CDRDER MT-3A elemental analyzer. X-ray diffraction analyses were measured on a Siemens P4 diffractometer.

2-(4-tert-Butylphenyl)-3-hydroxy-3-(1,3,4-trimethyl-1H-pyrazol-5-yl) acrylonitrile (3). A mixture of 4-tert-butylphenylacetonitrile $(3.60 \mathrm{~g}, 21.4 \mathrm{mmol})$, methyl 1,3,4trimethylpyrazol-5-carboxylate $(4.08 \mathrm{~g}, 23.4 \mathrm{mmol})$, ethylene glycol ether $(2 \mathrm{~mL})$ in heptane (40 $\mathrm{mL}$ ) was stirred at room temperature under a nitrogen atmosphere, then azeotropic dehydration was carried out under heating at 90 to $95{ }^{\circ} \mathrm{C}$ for $1 \mathrm{~h}$. To the reaction mixture, $28 \%$ sodium methoxide methanol solution $(6.20 \mathrm{~g}, 32.2 \mathrm{mmol})$ was added dropwise for $2 \mathrm{~h}$, and the resulting mixture was further reacted for $3 \mathrm{~h}$. After cooling to $30{ }^{\circ} \mathrm{C}$, the resulting mixture was extracted 
with water and ethyl acetate. The aqueous layer was acidified with concentrated hydrochloric acid $(3.2 \mathrm{~mL})$ and extracted with ethyl acetate. The organic layer was washed with saturated brine, dried over anhydrous $\mathrm{MgSO}_{4}$, and concentrated under reduced pressure to obtain $5.94 \mathrm{~g}$ (yield $90 \%$ ) of 3 , yellow crystalline solid, mp $175^{\circ} \mathrm{C}$ (lit.178 $\left.{ }^{\circ} \mathrm{C}\right) .{ }^{14}$

(2E)-3-(2,2-Dimethypropanoyloxy)-2-(4-tert-butylphenyl)-3-(1,3,4-trimethylpyrazol-5-yl)acrylonitrile (4). To the mixture of $3(3.09 \mathrm{~g}, 10.0 \mathrm{mmol})$, triethylamine $(1.11 \mathrm{~g}, 11.0 \mathrm{mmol})$ in THF (30 mL), 2,2-dimethylpropionyl chloride $(1.45 \mathrm{~g}, 12.0 \mathrm{mmol})$ was added dropwise at 25 to $27{ }^{\circ} \mathrm{C}$ over $10 \mathrm{~min}$. After reacting for $1 \mathrm{~h}$, THF was removed under a reduced pressure and the residue was partitioned between dichloromethane and water, the organic layer was washed with saturated brine and dried over anhydrous $\mathrm{MgSO}_{4}$. The solvent was again removed under reduce pressure and the residue was purified by column chromatography (ethyl acetate/petroleum ether, 1:10) to yield the title compound 4 as a white crystalline solid (3.66 g, 93\% yield), mp 106-107 ${ }^{\circ} \mathrm{C}$ (lit. 102-103 $\left.{ }^{\circ} \mathrm{C}\right) .{ }^{14} \mathrm{IR}(\mathrm{KBr}, \mathrm{cm}-1)$ v: $2210(\mathrm{CN}) .{ }^{1} \mathrm{H}$ NMR $\left(300 \mathrm{MHz}, \mathrm{CDCl}_{3}\right) \delta(\mathrm{ppm}): 1.17$ $\left(\mathrm{s}, 9 \mathrm{H}, \mathrm{C}\left(\mathrm{CH}_{3}\right)_{3}\right), 1.34\left(\mathrm{~s}, 9 \mathrm{H}, \mathrm{C}\left(\mathrm{CH}_{3}\right)_{3}\right), 2.10\left(\mathrm{~s}, 3 \mathrm{H}, \mathrm{CH}_{3}\right), 2.21\left(\mathrm{~s}, 3 \mathrm{H}, \mathrm{CH}_{3}\right), 3.91(\mathrm{~s}, 3 \mathrm{H}$, $\left.\mathrm{NCH}_{3}\right), 7.43-7.50(\mathrm{~m}, 4 \mathrm{H}, \mathrm{Ph}-\mathrm{H}) .{ }^{13} \mathrm{C} \mathrm{NMR}\left(75 \mathrm{MHz}, \mathrm{CDCl}_{3}\right) \delta(\mathrm{ppm}): 8.04,11.47,26.83,30.95$, 34.64, 37.06, 39.17, 76.57, 77.00, 77.43, 109.95, 115.30, 116.00, 125.91, 126.68, 127.40, 132.35, 146.80, 149.09, 152.80, 175.54. Anal. Calcd for $\mathrm{C}_{24} \mathrm{H}_{31} \mathrm{~N}_{3} \mathrm{O}_{2}$ : C, 73.25; H, 7.94; N,10.68; Found: C, 73.29; H, 7.97; N,10.70.

\section{(2Z)-3-(2,2-dimethypropanoyloxy)-2-(4-tert-butylphenyl)-3-(1,3,4-trimethylpyrazol-5-yl)-} acrylonitrile (5). To the mixture of $\mathbf{3}(2.00 \mathrm{~g}, 6.4 \mathrm{mmol}), 2$,2-dimethyl propionic acid $(0.73 \mathrm{~g}$, $7.1 \mathrm{mmol})$ and DMAP $(0.87 \mathrm{~g}, 7.1 \mathrm{mmol})$ in $\mathrm{CH}_{2} \mathrm{Cl}_{2}(15 \mathrm{~mL})$, DCC (1.48 $\left.\mathrm{g}, 7.1 \mathrm{mmol}\right)$ in $\mathrm{CH}_{2} \mathrm{Cl}_{2}(5 \mathrm{~mL})$ was added dropwise slowly. After reacting at room temperature over night, $\mathrm{CH}_{2} \mathrm{Cl}_{2}$ was removed under reduced pressure and the residue was partitioned between dichloromethane and water, the organic layer was washed with saturated brine and dried over sodium sulfate. The solvent was again removed under reduce pressure and the residue was purified by column chromatography (ethyl acetate/petroleum ether, 1:10) to yield the target molecule 5 as a white crystalline solid (1.63 g, 65\% yield), mp $147-148{ }^{\circ} \mathrm{C}$ (lit. $\left.146{ }^{\circ} \mathrm{C}\right) .{ }^{14} \mathrm{IR}$ $(\mathrm{KBr}, \mathrm{cm}-1)$ v: $2220(\mathrm{CN}) .{ }^{1} \mathrm{H}$ NMR $\left(300 \mathrm{MHz}, \mathrm{CDCl}_{3}\right) \delta(\mathrm{ppm}): 1.28\left(\mathrm{~s}, 9 \mathrm{H}, \mathrm{C}\left(\mathrm{CH}_{3}\right)_{3}\right), 1.35$ (s, 9H, $\left.\mathrm{C}\left(\mathrm{CH}_{3}\right)_{3}\right), 1.92$ (s, 3H, $\left.\mathrm{CH}_{3}\right), 2.17$ (s, 3H, $\left.\mathrm{CH}_{3}\right), 3.39$ (s, 3H, $\left.\mathrm{NCH}_{3}\right), 7.04$ (d, J 8.7 Hz, 2H, $\mathrm{Ph}-\mathrm{H}), 7.30$ (d, J $8.7 \mathrm{~Hz}, 2 \mathrm{H}, \mathrm{Ph}-\mathrm{H}) .{ }^{13} \mathrm{C} \mathrm{NMR}$ (75 MHz, $\mathrm{CDCl}_{3}$ ) $\delta$ (ppm): 8.61, 11.47, 26.60, 30.96, 34.64, 37.31, 39.11, 76.57, 77.00, 77.43, 110.70, 116.21, 116.78, 125.53, 126.92, 128.03, 133.37, 146.53, 149.64, 153.11,175.00. Anal. Calcd for $\mathrm{C}_{24} \mathrm{H}_{31} \mathrm{~N}_{3} \mathrm{O}_{2}: \mathrm{C}, 73.25 ; \mathrm{H}, 7.94 ; \mathrm{N}, 10.68$; Found: C, 73.30; H, 7.95; N,10.70.

\section{Method of transformation from 5 ( $Z$ form) into 4 (cyenopyrafen)}

A mixture of $5(4.00 \mathrm{~g}, 10.16 \mathrm{mmol})$ and pyridine $(0.48 \mathrm{~g}, 6.1 \mathrm{mmol})$ in acetonitrile $(50 \mathrm{~mL})$ was stirred and refluxed for $24 \mathrm{~h}$. The analysis with HPLC showed that the content of 4 was $55 \%$. The solvent was evaporated off, and the residue was purified by column chromatography (ethyl acetate/petroleum ether, 1:10) to give the compound 4 (1.92 g, $48 \%$ yield). The remaining of 5 was recycled to the next conversion until a full interconversion of 5 into 4 . 


\section{Biology assay}

All bioassays were performed on representative test organisms reared in the laboratory. The bioassay was repeated at $25 \pm 1{ }^{\circ} \mathrm{C}$ according to statistical requirements. Assessments were made on a dead/alive basis, and mortality rates were corrected using Abbott's formula. Evaluations are based on a percentage scale of $0-100$ in which $0=$ no activity and $100=$ total kill.

The acaricidal activities of the title compounds were tested against Spider Mites (Tetranychus cinnabarinus). The leaves of kidney bean plants were punched into $3 \mathrm{~cm}$-diamter discs, using leaf punch, and put onto moist filter paper in a $7 \mathrm{~cm}$-diameter styrol cup. Ten larvae spider mites (Tetranychus cinnabarinus) were put into each leaf. A 5\% emulsion of a compound was diluted with water containing a spreading agent to give a 1-10 ppm solution of the compound. The solution was sprayed over each cup in an amount of $2 \mathrm{~mL} / \mathrm{cup}$, using a rotary sprinkler. After 96 $\mathrm{h}$ passed, the mites in each cup were observed, and mortality of the mites was dertermined. The results of acaricidal activity are listed in Table 1.

\section{Acknowledgements}

We are grateful to the National Key Project of Scientific and Technology of China (NO. 2011BAE06B01-07) and National Program on Key Basic Research Project (973 Program No. 2010CB735601) for financial support.

\section{References}

1. Wolfgang, K.; Ulrich, S. In: Modern Crop Protection Compounds; Wiley-VCH: New York 2007, p 445.

2. Andreas, V. A.; Thomas, B.; Mazen, E. S.; Hendrik, H.; Wolfgang, T. Nachrichten aus der Chemie 2009, 57, 264.

3. Kusulka, Y.; Suzuki, H. WO Pat. Appl. 2,007,100,161, 2007; Chem. Abstr. 2007, 347, 344076.

4. Ogura, T. WO Pat. Appl. 974,009, 1997; Chem. Abstr. 1997, 127, 331484.

5. Cristina, F. F.; Nadine, J.; Ibon, A.; Celia, M. M.; Lourdes, I.; José, E. Arkivoc 2008, 8, 74.

6. Suzuki, H. JP. Pat. Appl. 2,008,208,047, 2007; Chem. Abstr. 2008, 149, 332328.

7. Nishioka, M.; Nakashita, H.; Suzuki, H.; Akiyama, S.; Yoshida, S.; Yamaguchi, I. J. Pesti. Sci. 2003, 28, 416.

8. Flores, A. F. C.; Moura, S.; Paula, F. R.; Pinto, E.; Machado, P.; Machado, P.; Martins, M. A. P. Lett. in Org. Chem. 2008, 5, 91.

9. Babu, S.; Dagnino, R. WO Pat. Appl. 2,006,048,761, 2006; Chem. Abstr. 2006, 144, 468155. 
10. Allen, J. R.; Hitchcock, S. A. WO Pat. Appl. 2,005,009,941, 2005; Chem. Abstr. 2005, 142, 197700.

11. Chen, Z. Y.; Hu, L. M.; Li, X. S.; Liu, Z. J. Huazhong Shifan Daxue Xuebao 2003, 37, 215.

12. Andreas, S.; Tobias, H.; Markus, K. K.; Martin, N. J. Org. Chem. 2003, 68, 5977.

13. Bessard, Y.; Leresche, J. WO. Pat. Appl. 107,410, 2001; Chem. Abstr. 2001, 134, 131435.

14. Kenzo, F.; Yasuo.k.; Norio, T.; Hideaki, S.; Masatoshi, O.; Koichi, N. WO. Pat. Appl. 2,004,087,674, 2004; Chem. Abstr. 2004, 141,332188.

15. Yang, P.; Shen, D. L.; Tan, C.; Weng, J.; Lu, Q.; Wei, Y.; Kong, X. Zhejiang Daxue Xuebao 2009, 36, 183.

16. Umadevi, S.; Sadashiva, B. K. Chem. Mater. 2006, 18, 5186.

17. Matsui, N. WO Pat. Appl. 2,003,031,421, 2003; Chem. Abstr. 2003, 138, 304275.

18. Sun, Z. Y.; Hosmane, R. S.; Tadros, M. Heterocycl. Chem. 2000, 37, 1439.

19. Dugave, P.; Demange, L. Chem. Rev. 2003, 103, 2475. 